\title{
The role of protein dynamics in allosteric effects-introduction
}

\author{
Gordon Roberts ${ }^{1}$
}

Received: 13 April 2015 /Accepted: 13 April 2015 / Published online: 9 May 2015

(C) International Union for Pure and Applied Biophysics (IUPAB) and Springer-Verlag Berlin Heidelberg 2015

Certainly no subject or field is making more progress on so many fronts at the present moment, than biology, and if we were to name the most powerful assumption of all, which leads one on and on in an attempt to understand life, it is that all things are made of atoms, and that everything that living things do can be understood in terms of the jigglings and wigglings of atoms.

Richard Feynman

(Feynman Lectures on Physics, vol. 1, Ch. 3. 1963; http:// www.feynmanlectures.caltech.edu/)

Control at the molecular level is an essential feature of cellular function, and a key mechanism of this control is 'allosteric' regulation, a concept introduced some 50 years ago by Monod, Changeux, Jacob and Wyman (see (Changeux 2012, 2013; Changeux and Edelstein 2005)) and which is as important now as it was then. The central idea of allosteric regulation is that interaction of a ligand at one site on a protein can change the functional (binding or catalytic) properties at another site without direct spatial proximity of the two sites. While the initial 'MWC' model for allosteric effects focussed on oligomeric proteins existing in two conformational states (Monod et al. 1965), subsequent work has led to a number of extensions to the concept. First, it is clear that monomeric proteins can show functionally important allosteric effects-

This article is part of a Special Issue on 'The Role of Protein Dynamics in Allosteric Effects' edited by Gordon Roberts.

Gordon Roberts

gcr@le.ac.uk

1 Henry Wellcome Laboratories of Structural Biology, Department of Biochemistry, University of Leicester, Leicester LE1 9HN, UK for example, the regulatory proteins $\mathrm{CheY}$ and $\mathrm{NtrC}$ (Cui and Karplus 2008; McDonald et al. 2012; Villali et al. 2014; Volkman et al. 2001). The transmission of the effects of distal mutations is analogous in many ways to the transmission of the effects of ligand binding, and is of course seen in many monomeric proteins (e.g., Clarkson et al. 2006; Lee and Goodey 2011), while it has been studied in particular detail in dihydrofolate reductase (Boehr et al. 2013; Wong et al. 2005). Secondly, such effects are clearly not restricted to small molecule ligands - allosteric effects involving the binding of other macromolecules or covalent modification (such as phosphorylation) are of fundamental importance in the regulation of signal transduction and of metabolism. Thirdly, the concept of population shifts between pre-existing states, the basis of the MWC model, has been discussed more broadly within the 'energy landscape' or 'ensemble' formalism (Frauenfelder et al. 1991; Hilser et al. 2012; Itoh and Sasai 2010; Motlagh et al. 2014) and has also come to the fore thanks to the recent development of NMR methods for detecting and characterising conformational states present in low populations (Baldwin and Kay 2009; Manley and Loria 2012; Mittermaier and Kay 2006; Sekhar and Kay 2013).

The prevailing view of allostery still tends to focus on structure. Yet, since allostery is fundamentally thermodynamic in nature, involving changes in enthalpy and/or entropy, communication across the protein could be mediated not only by changes in the mean conformation but also by changes in the dynamic fluctuations about the mean conformation (Cooper and Dryden 1984; Tsai et al. 2008). Thirty years ago, Cooper and Dryden (1984) noted that in principle even in the absence of a ligand-induced change in the time-averaged conformation, changes in protein dynamics leading to changes in the distribution around the average structure could produce allosteric communication between distinct binding sites. They showed that free energies of a few $\mathrm{kcal} / \mathrm{mol}$ can be derived 
from only a slight stiffening of a few of the many global dynamic modes of motion available to a protein. With the increasing understanding of the importance of dynamics in enzyme catalysis (see the recent virtual special issue of $A c$ counts of Chemical Research on 'Protein Motions in Catalysis'; Bhabha et al. 2015; Callender and Dyer 2015; Hanoian et al. 2015; Klinman 2015; Kohen 2015; Palmer 2015) and in protein function in general, the importance of dynamics as a contributory mechanism in allosteric effects is now recognised (Jardetzky 1996; Kern and Zuiderweg 2003; Tsai et al. 2008).

In the last few years, there have been a number of reports describing clear roles for protein dynamics in allosteric effects, both in the transitions between states and in making substantial contributions to the thermodynamics of the allosteric effect itself (Jiao et al. 2012; Kern and Zuiderweg 2003; Law et al. 2014; Manley and Loria 2012; McElroy et al. 2002; Palazzesi et al. 2013; Popovych et al. 2006; Rivalta et al. 2012; Shi and Kay 2014; Stevens et al. 2001). (It is of course difficult to demonstrate the existence of allosteric effects produced solely by changes in dynamics, since the failure to observe a structural change does not mean that it does not occur; Nussinov and Tsai 2014.)

Bearing in mind the 50th anniversary of the Monod, Wyman and Changeux paper and the 30th anniversary of the Cooper and Dryden paper, we felt that it would be timely and interesting to review the current concepts on 'The Role of Protein Dynamics in Allosteric Effects' in a dedicated issue of Biophysical Reviews.

This issue includes reviews of specific examples where there is clear evidence for the importance of dynamics in allosteric effects. There are discussions of monomeric proteins such as the PBX1 homeodomain (Mittermaier 2015) and CheY (Lee 2015), the dimeric catabolite activator protein (CAP; (Townsend 2015; Tzeng 2015), the tetrameric protein kinase A (Ping 2015) and a number of multi-domain proteins (Lee 2015; Motlagh 2015; Peng 2015; Whitney 2015) and finally the large pentameric acetylcholine receptor channel (Changeux 2014). Many of these examples show the importance of global low-frequency protein fluctuations in allosteric effects, and a successful theoretical approach to these by normal mode analysis is discussed by Townsend et al. (Townsend 2015). Several articles discuss the use of NMR spectroscopy to study the dynamic effects of interest, and Mittermaier and Farber (Mittermaier 2015) describe the use of relaxation dispersion NMR in detail; other new physical methods of considerable potential value in this area are neutron spin echo spectroscopy (Callaway 2015) and terahertz spectroscopy (Niessen 2015).

\section{References}

Baldwin AJ, Kay LE (2009) NMR spectroscopy brings invisible protein states into focus. Nat Chem Biol 5:808-814. doi:10.1038/nchembio. 238
Bhabha G, Biel JT, Fraser JS (2015) Keep on moving: discovering and perturbing the conformational dynamics of enzymes. Acc Chem Res 48:423-430. doi:10.1021/ar5003158

Boehr DD et al (2013) A distal mutation perturbs dynamic amino acid networks in dihydrofolate reductase. Biochemistry 52:4605-4619. doi:10.1021/bi400563c

Callaway DJE, Bu Z (2015) Nanoscale protein domain motion and longrange allostery in signaling proteins - a view from neutron spin echo spectroscopy. Biophys Rev. doi:10.1007/s12551-015-0162-x

Callender R, Dyer RB (2015) The dynamical nature of enzymatic catalysis. Acc Chem Res 48:407-413. doi:10.1021/ar5002928

Changeux J-P (2012) Allostery and the Monod-Wyman-Changeux model after 50 years. Annu Rev Biophys 41:103-133. doi:10.1146/ annurev-biophys-050511-102222

Changeux J-P (2013) 50 years of allosteric interactions: the twists and turns of the models. Nat Rev Mol Cell Biol 14:819-829

Changeux J-P (2014) Protein dynamics and the allosteric transitions of pentameric receptor-channels. Biophys Rev. doi:10.1007/s12551014-0149-z

Changeux JP, Edelstein SJ (2005) Allosteric mechanisms of signal transduction. Science 308:1424-1428

Clarkson MW, Gilmore SA, Edgell MH, Lee AL (2006) Dynamic coupling and allosteric behavior in a nonallosteric protein. Biochemistry 45:7693-7699. doi:10.1021/bi0606521

Cooper A, Dryden D (1984) Allostery without conformational change. A plausible model. Eur Biophys J 11:103-109

Cui Q, Karplus M (2008) Allostery and cooperativity revisited. Protein Sci 17:1295-1307

Frauenfelder H, Sligar SG, Wolynes PG (1991) The energy landscapes and motions of proteins. Science 254:1598-1603

Hanoian P, Liu CT, Hammes-Schiffer S, Benkovic S (2015) Perspectives on electrostatics and conformational motions in enzyme catalysis. Acc Chem Res 48:482-489. doi:10.1021/ar500390e

Hilser VJ, Wrabl JO, Motlagh HN (2012) Structural and energetic basis of allostery. Annu Rev Biophys 41:585-609. doi:10.1146/annurevbiophys-050511-102319

Itoh K, Sasai M (2010) Entropic mechanism of large fluctuation in allosteric transition. Proc Natl Acad Sci U S A 107:7775-7780. doi:10. 1073/pnas.0912978107

Jardetzky O (1996) Protein dynamics and conformational transitions in allosteric proteins. Prog Biophys Mol Biol 65:171-219

Jiao W, Hutton RD, Cross PJ, Jameson GB, Parker EJ (2012) Dynamic cross-talk among remote binding sites: the molecular basis for unusual synergistic allostery. J Mol Biol 415:716-726

Kern D, Zuiderweg ER (2003) The role of dynamics in allosteric regulation. Curr Opin Struct Biol 13:748-757

Klinman JP (2015) Dynamically achieved active site precision in enzyme catalysis. Acc Chem Res 48:449-456. doi:10.1021/ar5003347

Kohen A (2015) Role of dynamics in enzyme catalysis: substantial versus semantic controversies. Acc Chem Res 48:466-473. doi:10.1021/ ar500322s

Law SM, Gagnon JK, Mapp AK, Brooks CL 3rd (2014) Prepaying the entropic cost for allosteric regulation in KIX. Proc Natl Acad Sci U S A 111:12067-12072. doi:10.1073/pnas.1405831111

Lee A (2015) Contrasting roles of dynamics in protein allostery: NMR and structural studies of CheY and the third PDZ domain from PSD95. Biophys Rev. doi:10.1007/s12551-015-0169-3

Lee J, Goodey NM (2011) Catalytic contributions from remote regions of enzyme structure. Chem Rev 111:7595-7624. doi:10.1021/ cr100042n

Manley G, Loria JP (2012) NMR insights into protein allostery. Arch Biochem Biophys 519:223-231. doi:10.1016/j.abb.2011.10.023

McDonald LR, Boyer JA, Lee AL (2012) Segmental motions, not a twostate concerted switch, underlie allostery in CheY. Structure 20: 1363-1373. doi:10.1016/j.str.2012.05.008 
McElroy C, Manfredo A, Wendt A, Gollnick P, Foster M (2002) TROSYNMR studies of the $91 \mathrm{kDa}$ TRAP protein reveal allosteric control of a gene regulatory protein by ligand-altered flexibility. J Mol Biol 323:463-473

Mittermaier A, Farber PJ (2015) Relaxation dispersion NMR spectroscopy for the study of protein allostery. Biophys Rev. doi:10.1007/ s12551-015-0166-6

Mittermaier A, Kay LE (2006) New tools provide new insights in NMR studies of protein dynamics. Science 312:224-228. doi:10.1126/ science.1124964

Monod J, Wyman J, Changeux J-P (1965) On the nature of allosteric transitions: a plausible model. J Mol Biol 12:88-118

Motlagh HN, Wrabl JO, Li J, Hilser VJ (2014) The ensemble nature of allostery. Nature 508:331-339

Motlagh HN, Anderson J, Li J, Hilser VJ (2015) Disordered allostery: lessons from glucocorticoid receptor. Biophys Rev. doi:10.1007/ s12551-015-0173-7

Niessen KA, Xu M, Markelz A (2015) Terahertz optical measurements of correlated motions with possible allosteric function. Biophys Rev. doi:10.1007/s12551-015-0168-4

Nussinov R, Tsai C (2014) Allostery without a conformational change? Revisiting the paradigm. Curr Opin Struct Biol 30:17-24. doi:10. 1016/j.sbi.2014.11.005

Palazzesi F, Barducci A, Tollinger M, Parrinello M (2013) The allosteric communication pathways in KIX domain of CBP. Proc Natl Acad Sci U S A 110:14237-14242. doi:10.1073/pnas.1313548110

Palmer AG (2015) Enzyme dynamics from NMR spectroscopy. Acc Chem Res 48:457-465. doi:10.1021/ar500340a

Peng JW (2015) Investigating dynamic interdomain allostery in Pin1. Biophys Rev. doi:10.1007/s12551-015-0171-9

Ping Z, Kornev AP, Wu J, Taylor SS (2015) Discovery of allostery in PKA signaling. Biophys Rev. doi:10.1007/s12551-015-0170-x

Popovych N, Sun S, Ebright RH, Kalodimos CG (2006) Dynamically driven protein allostery. Nat Struct Mol Biol 13:831-838. doi:10. 1038/nsmb1132

Rivalta I, Sultan MM, Lee NS, Manley GA, Loria JP, Batista VS (2012) Allosteric pathways in imidazole glycerol phosphate synthase. Proc
Natl Acad Sci U S A 109:1428-1436. doi:10.1073/pnas. 1120536109

Sekhar A, Kay LE (2013) NMR paves the way for atomic level descriptions of sparsely populated, transiently formed biomolecular conformers. Proc Natl Acad Sci U S A 110:12867-12874. doi:10. 1073/pnas. 1305688110

Shi L, Kay LE (2014) Tracing an allosteric pathway regulating the activity of the HslV protease. Proc Natl Acad Sci U S A 111:2140-2145. doi:10.1073/pnas.1318476111

Stevens SY, Sanker S, Kent C, Zuiderweg ER (2001) Delineation of the allosteric mechanism of a cytidylyltransferase exhibiting negative cooperativity. Nat Struct Biol 8:947-952. doi:10. 1038/nsb1101-947

Townsend PD, Rogers TL, Pohl E, Wilson MR, McLeish TCB, Cann M (2015) Global low-frequency motions in protein allostery: CAP as a model system. Biophys Rev. doi:10.1007/ s12551-015-0163-9

Tsai CJ, del Sol A, Nussinov R (2008) Allostery: absence of a change in shape does not imply that allostery is not at play. J Mol Biol 378:111. doi:10.1016/j.jmb.2008.02.034

Tzeng S-R, Kalodimos C (2015) The role of slow and fast protein motions in allosteric interactions. Biophys Rev. doi:10.1007/s12551015-0172-8

Villali J, Pontiggia F, Clarkson MW, Hagan MF, Kern D (2014) Evidence against the "Y-T coupling" mechanism of activation in the response regulator NtrC. J Mol Biol 426:1554-1567. doi:10.1016/j.jmb. 2013.12.027

Volkman BF, Lipson D, Wemmer DE, Kern D (2001) Two-state allosteric behavior in a single-domain signaling protein. Science 291:24292433. doi:10.1126/science.291.5512.2429

Whitney DS, Volkman BF (2015) Some (dis)assembly required: partial unfolding in the Par-6 allosteric switch. Biophys Rev. doi:10.1007/ s12551-015-0164-8

Wong KF, Selzer T, Benkovic SJ, Hammes-Schiffer S (2005) Impact of distal mutations on the network of coupled motions correlated to hydride transfer in dihydrofolate reductase. Proc Natl Acad Sci U S A 102:6807-6812. doi:10.1073/pnas.0408343102 